\title{
The Sylvian aqueduct syndrome and neurofibromatosis
}

\author{
JOHN S. LEAN \\ From the National Hospital for Nervous Diseases, Queen Square, London
}

SUMMARY A 23-year-old man initially presented with the Sylvian aqueduct syndrome and subseqently developed cutaneous neurofibromata. The case is reported and the possibility that these represent manifestations of the same genetic abnormality is discussed.

Ophthalmic manifestations of neurofibromatosis are well recognised, and indeed involvement of the eye and its adnexa with neurofibromata has been reported in every structure except the lens and vitreous. ${ }^{1}$ However, these are usually seen in the anterior visual system ${ }^{2}$ and reflect the regional hypertrophy of the neural and connective tissue elements that occurs in this condition. ${ }^{3}$ Abnormalities of the central nervous system are less commonly found in neurofibromatosis, and apart from the well recognised association with optic nerve and chiasmal gliomas ${ }^{4}$ these rarely present to the ophthalmologist. The purpose of this paper is to report a case with the classical neuro-ophthalmic presentation of the Sylvian aqueduct syndrome in which subcutaneous neurofibromata have subsequently developed.

The Sylvian aqueduct syndrome is most commonly due to a pineal tumour, although occasionally encephalitis, vascular occlusion, or a midbrain glioma may produce similar symptoms. ${ }^{5}$ However, the precise diagnosis is usually presumptive, based on the presence of associated clinical signs and a successful trial of radiotherapy, since surgical exploration is still hazardous in this area. In the case under review the original presentation was thought typical of a pineal tumour. However, the subsequent development of characteristic cutaneous stigmata suggests that the initial midbrain syndrome was an unusual manifestation of neurofibromatosis. So far as we are aware this association has not previously been reported.

\section{Case report}

A 23-year-old man was admitted to hospital in May 1969 with symptoms of raised intracranial pressure and diplopia. He had first presented to an optician

Correspondence to Mr J. S. Lean, Moorfields Eye Hospital, City Road, London EC1V 2PD.
9 months earlier complaining of difficulty with his distance vision. He was prescribed a small myopic correction for distance vision in both eyes, with initial improvement. However, 2 months before admission he began to have difficulty with near vision and to notice vertical diplopia. Both these symptoms persisted, and in addition he developed severe headaches and vomiting, which precipitated his admission.

On examination he was found to have a correctable vision of $6 / 5, \mathrm{~N} 5$ in each eye. There was a dissociated deficit of upgaze with relative loss of saccadic movement but preservation of smooth pursuit movement. Attempts at rapid upward saccades evoked convergence retraction nystagmus. A skew deviation was present, with left hypotropia. The pupillary responses showed light near dissociation. There was bilateral chronic papilloedema. A clinical diagnosis of the Sylvian aqueduct syndrome was made.

Investigation by pneumoencephalography revealed symmetrical hydrocephalus (Fig. 1) with obstruction of the Sylvian aqueduct (Fig. 2). A Torkildsen shunt was performed and the midbrain region treated with 5000 rads in divided doses. His symptoms of raised intracranial pressure were rapidly relieved, but the oculomotor and pupillary disturbance have persisted.

He had no further problems until 1976, when he presented to the Skin Department with small painless lumps on his abdomen; these had appeared over the previous year. A biopsy of one of them showed the typical features of neurofibromata (Fig. 3). Since then these lesions have remained unchanged.

\section{Discussion}

The Sylvian aqueduct syndrome is a classical constellation of neuro-ophthalmological signs which 


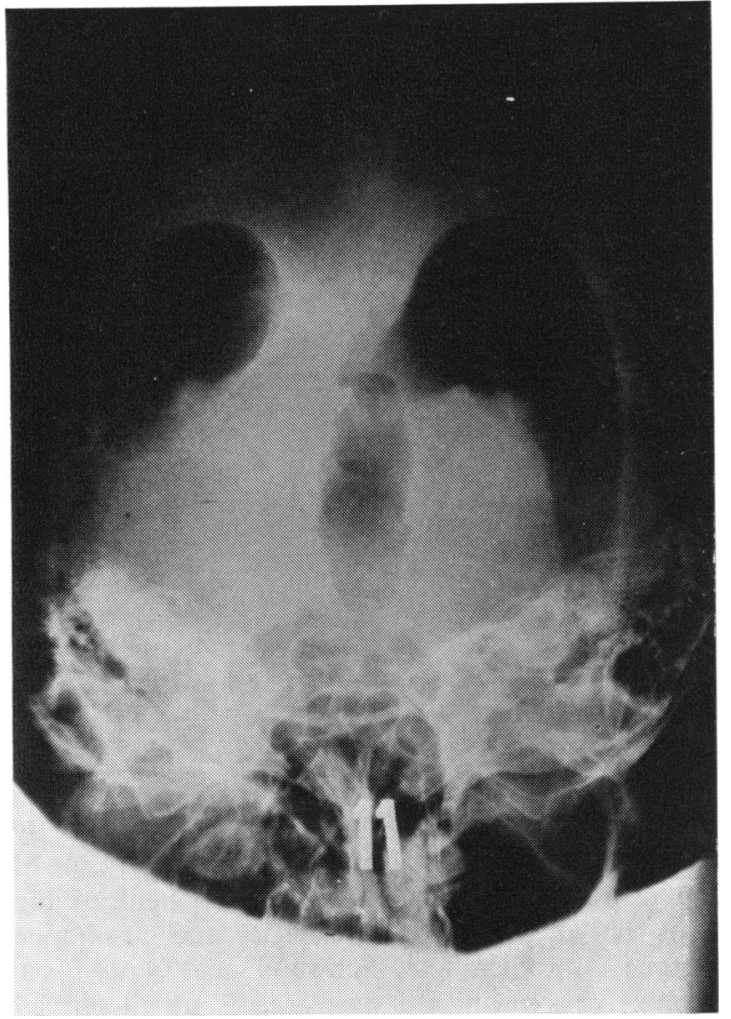

Fig. 1 Air ventriculogram. Towne's projection. There is marked hydrocephalus, with considerable enlargement of the third ventricle. were initially described by Parinaud and attributed to compression of the pretectal region. The initial presentation of this patient with acquired myopia is unusual but well recorded. ${ }^{6}$ The commonest cause of the syndrome is a pineal tumour, of which the majority are atypical teratomas. ${ }^{7}$ However, in a recent series of neurosurgical explorations $25 \%$ of tumours in this region were found to be nonpineal in origin. ${ }^{8}$ In this patient the development of cutaneous neurofibromata 8 years after the original midbrain syndrome suggests that the 2 lesions are related and the underlying pathology the same.

Abnormalities of the central nervous system are well recognised in neurofibromatosis. The incidence in published series ranges from $3 \%{ }^{9}$ to $19 \%{ }^{10} \mathrm{~A}$ wide range of abnormalities have been reported, from neoplastic gliomata to glial heterotopias and other dysplastic malformations. The most frequently found glioma is the optic nerve and chiasmal astrocytoma of childhood, ${ }^{4}$ but similar gliomata occur in the intracranial cavity, either as single ${ }^{11}$ or as multiple lesions ${ }^{1213}$ and occasionally as diffusely infiltrative tumours. ${ }^{14}$ Meningiomas are also associated, and they may be multiple. ${ }^{15}$ Non-neoplastic malformations of the central nervous system are also regularly found in neurofibromatosis and have recently been extensively reviewed. ${ }^{16}$ These central forms of neurofibromatosis are often found in the absence of extensive peripheral disease. Indeed, to some extent the peripheral and central manifestations of neurofibromatosis are mutually exclusive. ${ }^{17}$ In a recent review of 10 cases of neurofibromatosis

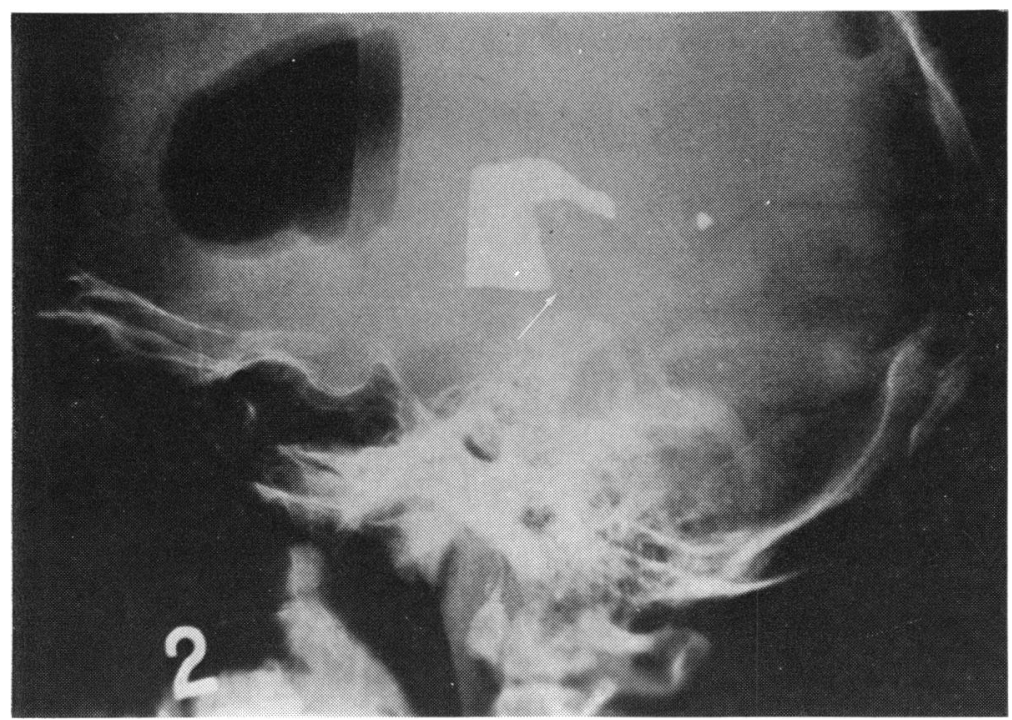

Fig. 2 Lateral projection, 'brow up' position. Iophendylate (Myodil) has now been injected. It outlines the posterior end of the third ventricle and the dilated upper portion of the Sylvian aqueduct, but does not pass beyond this (arrow). The suprapineal recess is prominent, but there is no evidence of an extrinsic mass lesion. The appearances are those of occlusion of the aqueduct. 
Fig. 3 A composite photomicrograph showing an extensive neurofibroma in the deeper levels of the reticular dermis. (×75.)

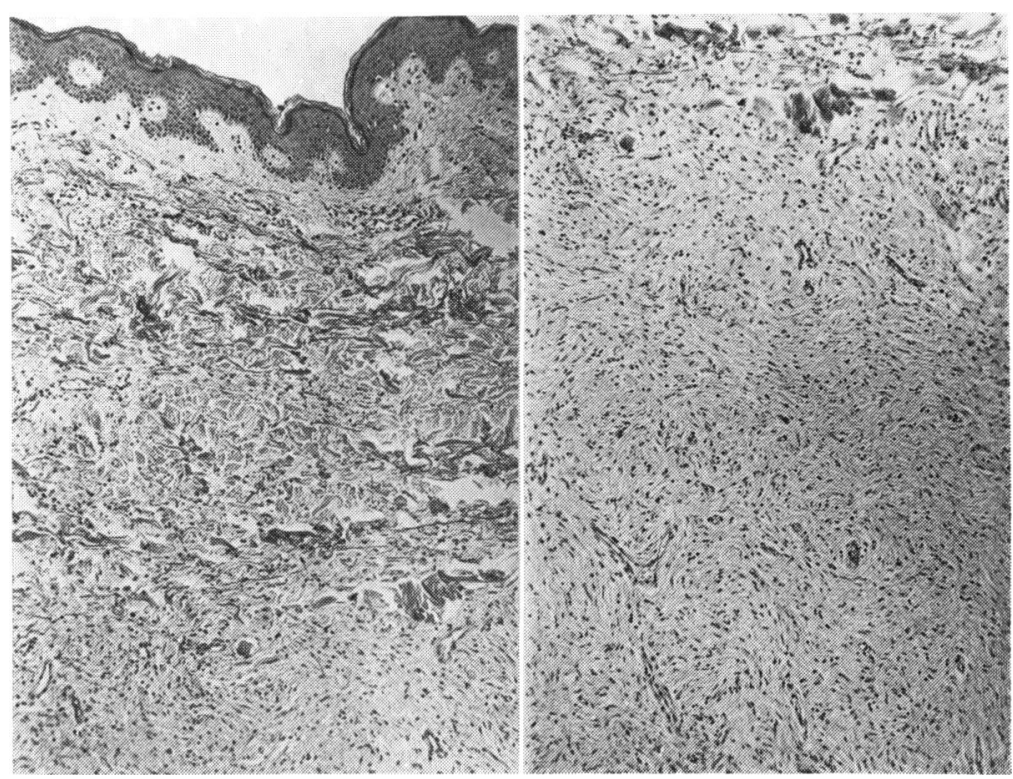

neural ectoderm and neural crest derivatives. ${ }^{3}$ By proliferation, differentiation, and migration cells of the neural crest form a major component of the adult nervous system. The sensory and autonomic ganglia, leptomeninges, Schwann cells, and some supportive connective tissue elements are all derived from this embryonic tissue. In addition some glial and neurilemmal cells of the central nervous system may arise from the neural crest or may originate as a distinct cell population in the neural folds. ${ }^{21}$ Dysplastic or frankly neoplastic change in this second group of cells is thought to be responsible for the lesions seen in central forms of neurofibromatosis. In the case under review the absence of progression suggests that dysplasia of these central glial or neurilemmal cells is the most likely cause of the midbrain syndrome, and furthermore, that a common origin in neural ectoderm forms the link between these 2 apparently unrelated clinical symptoms.

I am grateful to Professor John Marshall for permission to publish details of this case and to $\mathrm{Mr}$ M. D. Sanders for helpful criticism in the preparation of the text. Dr Ivan Moseley kindly provided the radiographic reports, and the Department of Dermatology, St Thomas's Hospital, provided histopathology of the skin biopsy. My thanks are also due to Miss Denise Bryant for secretarial assistance.

\section{References}

${ }^{1}$ Marshall D. Glioma of the optic nerve as a manifestation of von Recklinghausen's disease. Am J Ophthalmol 1954; 37: 15-36.

${ }^{2}$ Krill AE. Hereditary Retinal and Choroidal Diseases. Hagerstown: Harper and Row, 1977: 2: 1210-3. 
${ }^{3}$ Bolande RP. The neurocristopathies-a unifying concept of disease arising in neural crest maldevelopment. Hum Pathol 1974; 5: 409-29.

${ }^{4}$ Davis FA. Primary tumours of the optic nerve (a phenomenon of von Recklinghausen's disease). Arch Ophthalmol 1940; 23: 735, 957.

${ }^{5}$ Walshe FB, Hoyt FW. Clinical Neuro-ophthalmology. Baltimore: Williams and Wilkins, 1969: 1: 228.

${ }^{6}$ Sanders MD, Bird AC. The supranuclear abnormalities of the vertical oculomotor system. Trans Ophthalmol Soc UK $1970 ; 90$ : 433-49.

${ }^{7}$ Russell DS, Rubinstein LJ. Pinealomas. Pathology of Tumours of the Nervous System. London: Arnold, 1971: 171-82.

${ }^{8}$ Poppen JL, Marino R. Pinealomas and tumours of the posterior portion o the third ventricle. $J$ Neurosurg 1968 ; 28: 357-61.

${ }^{9}$ Crowe FW, Schull WJ, Neel JV. Multiple Neurofibromatosis. Springfield: Thomas, 1956: 43.

${ }^{10}$ Harkin JC, Reed RJ. Tumours o the peripheral nervous sysiem. Atlas of Tumour Pathology. Washington DC: Armed Forces Institute of Pathology: fascicle 3, series 2.

${ }^{11}$ Canale DJ, Bebin J, Knighton RS. Neurological manifestations of von Recklinghausen's disease of the nervous system. Confin Neurol 1964; 24: 359-403.
${ }^{12}$ Davison C. Von Recklinghausen's disease with glioblastoma multiforme and ganglioneuroma. J Nerv Ment Dis 1941; 93: 73-4.

${ }^{13}$ Pearce J. The central nervous system pathology in multiple neurofibromatosis. Neurology 1967; 17: 691-7.

${ }^{14}$ Nevin S. Gliomatosis cerebri. Brain 1938; 61: 170-91.

${ }^{15}$ Cushing HW, Eisenhardt L. The Menigiomas. Springfield: Thomas, 1938: 103-5.

${ }^{16} \mathrm{Kramer} \mathrm{W}$. Lesions of the central nervous system in multiple neurofibromatosis. Psychiatr Pol 1971 ; 74: 349-65.

${ }^{17}$ Alliez J. Localisations centrales dans la neurogliomatose de Recklinghausen. In: Handbook of Clinical Neurology. New York: North Holland Publishing and American Elsevir Publishing, 1933: 14: 33-4.

${ }^{18}$ Russell DS, Rubinstein LJ. Central nervous system. Pathology of Tumours of the Nervous System. London: Arnold, 1973: 32-3.

${ }^{19}$ Russell DS. Observations on the pathology of hydrocephalus. Med Res Cncl Rep 1949; 265: 48-50.

${ }^{20}$ Descuns P, Charbonnel A, Collet M, Giudicelli G, Resche F, Lajat $Y$. Stenose extrinsique de l'aquedic de Sylvius et maladie de Recklinghausen. Otol Neurol Ophthalmol 1973; 45: 85-8.

${ }^{21}$ Weston JA. The migration and differentiation of neural crest cells. Adv Morphol 1970; 8: 11-20. 